\title{
Pembuatan Portal Kegiatan Perkuliahan Bagi Dosen Sistem Komputer UNDIP
}

\author{
Dyah Mustika Nency Widowati, Kodrat Iman Satoto, Kurniawan Teguh Martono \\ Program Studi Sistem Komputer, Fakultas Teknik, Universitas Diponegoro \\ Jln. Prof. Sudharto, Tembalang, Semarang, Indonesia \\ Email: nencyeunike@yahoo.com
}

\begin{abstract}
In any lectures, the lecturer must fill journal lectures. Journal of the activity is used to determine the subject matter of the lecture material delivered. In addition as an evaluation if there is material that has not been delivered. Each journal lectures will be always monitored by the Head of the Department to meet its obligations if the lecturers in teaching or not. In the process of implementation, all lectures still be entered manually using paper. It made less cumbersome and complicates monitoring of the Head of Department to monitor any lectures. So the need for making the portal lectures to assist monitoring and lectures journal entry.
\end{abstract}

Making these lectures portals using PHP programming language and MySQL database. As well as using the waterfall method and blackbox testing. Waterfall method includes user requirements, analysis, design, implementation and testing. Blackbox testing is used to test the program without the test of functional design specifications and program code. Used also Entity Relationship Diagram, Data Flow Diagram and in the design of the information system .

The results of the application design in the form of web-based desktop application, which is easier for professors to fill any lectures that have been done, knowing the schedule of lectures and the material that was presented at each meeting. As well as Head of the Department to facilitate monitoring any existing faculty .

Keywords : MySQL, PHP, Blackbox testing, application

\section{PENDAHULUAN}

$\mathrm{S}$ emakin berkembangnya dunia pendidikan, terutama pada perguruan tinggi membutuhkan sebuah aplikasi yang dapat memantau setiap kegiatan perkuliahan. Setiap dosen diwajibkan untuk mengisi jurnal kegiatan perkuliahan selama mengajar. Jurnal kegiatan ini berisi mengenai semua materi yang disampaikan pada setiap pertemuan perkuliahan. Dengan adanya jurnal kegiatan ini, dosen akan mengetahui materi yang sudah disampaikan dan jumlah mahasiswa yang menghadiri mata kuliah tersebut.

Selain itu, jurnal kegiatan perkuliahan tersebut digunakan untuk memantau dosen, apakah telah memenuhi tugas mengajar sesuai dengan kontrak perkuliahan yang telah ditentukan.

Jurusan Sistem Komputer UNDIP belum memiliki portal untuk mengisi jurnal kegiatan perkuliahan secara online. Selama ini semua kegiatan perkuliahan masih diisi secara manual menggunakan kertas. Hal tersebut membuat kurang praktis dan mempersulit pemantauan dari pihak Kepala Jurusan untuk memantau setiap kegiatan perkuliahan.

Salah satu perguruan tinggi yang telah melakukan penelitian mengenai aplikasi sejenis adalah STIKOM Bali yang mengembangkan sistem kehadiran dosen. Pengembangan sistem kehadiran dosen dilakukan oleh I Gusti Rai Agung Sugiarta dan Ni Nyoman Harini Puspita. Sistem ini digunakan untuk mengetahui kehadiran dosen dan mengetahui jadwal kegiatan belajar mengajar (I Gusti Rai Agung Sugiarta, Ni Nyoman Harini Puspita, 2011).

Jurnal kegiatan perkuliahan sangat penting bagi sebuah jurusan. Sehingga perlu dibuat sebuah portal untuk jurnal kegiatan perkuliahan. Dengan adanya pembuatan portal tersebut, diharapkan setiap dosen akan lebih mudah untuk mengisi jurnal kegiatan perkuliahan dan mengetahui jadwal serta materi yang sudah disampaikan selama perkuliahan. Serta memudahkan pemantauan kegiatan perkuliahan oleh Kepala Jurusan.

\section{TINJAUAN PUSTAKA}

\section{A. $P H P$}

PHP (PHP: Hypertext Preprocessor) adalah sebuah bahasa pemrograman yang berbentuk Scripting, sistem kerja dari program ini adalah sebagai interpreter bukan sebagai Compiler. Perbedaan antara bahasa Compiler dan bahasa Intepreter adalah sebagai berikut:

a. Bahasa Compiler

Bahasa Compiler adalah bahasa yang akan mengubah script-script program ke dalam source code, selanjutnya dari bentuk source code akan diubah menjadi bentuk dari objek kode. Program yang dihasilkan akan berbentuk .EXE. Contoh dari program Compiler adalah Pascal, C, Delpi maupun Visual Basic.

\section{b. Bahasa Interpreter}

Pada bahasa Interpreter, script mentahnya tidak harus diubah kedalam source code. Sehingga pada saat menjalankan bentuk program, kode dasar secara langsung akan dijalankan. Kekurangan dari bentuk Intepreter adalah program pembuatnya harus selalu tersedia dan berjalan saat mengaktifkan program yang dibuat. Sehingga hasil dari program ini sebenarnya bukan merupakan program yang dapat dieksekusi secara mandiri tanpa menggunakan program pembuatnya. Contoh program yang berupa Interpreter adalah PHP, Java dan Perl (Nugroho, 2004).

Keunggulan PHP antara lain: Gratis, Cross platform, Mendukung banyak database, On The Fly

\section{B. $H T M L$}

Hypertext Markup Language (HTML) adalah bahasa markup yang umum digunakan untuk membuat halaman web. Pada halaman Web, HTML dijadikan sebagai Bahasa Script dasar yang berjalan bersama berbagai bahasa Scripting pemrograman lainnya. Semua tag-tag HTML bersifat dinamis, artinya kode HTML tidak dapat dijadikan sebagai file Executable program. Hal ini disebabkan HTML hanyalah sebuah bahasa scripting yang dapat berjalan apabila JTSiskom - 157 
dijalankan di dalam browser. Jadi saat ingin membuka halaman yang berasal dari HTML, dapat melihat bentuk pengkodeannya dengan cara mengklik menu View $\rightarrow$ Source maka akan ditampilkan Tag beserta isi dari halaman web tersebut (Nugroho, 2004).

\section{Basis Data}

Basis data adalah kumpulan informasi yang disimpan di dalam komputer secara sistematik sehingga dapat diperiksa menggunakan suatu program komputer untuk memperoleh informasi dari basis data tersebut.

\section{ANALISIS DAN PERANCANGAN SISTEM}

\section{A. Analisis Kebutuhan Sistem}

Analisis kebutuhan fungsional pada sistem ini diperlukan dalam mendukung kinerja dari sistem, Fungsi sistem yang dibuat meliputi:

1. Adanya fasilitas Login untuk membagi hak akses pengguna sesuai dengan username dan password yang diberikan.

2. Adanya fasilitas admin untuk menambah user baru.

3. Adanya fasilitas admin untuk mengubah dan menghapus user yang telah dimasukkan.

4. Adanya fasilitas tatausaha untuk menambah jadwal kuliah baru.

5. Adanya fasilitas tatausaha untuk mengubah dan menghapus jadwal kuliah yang telah dimasukkan.

6. Adanya fasilitas dosen untuk melihat jadwal kuliah.

7. Adanya fasilitas dosen untuk melihat peserta matakuliah.

8. Adanya fasilitas dosen untuk mengisi kegiatan perkuliahan.

9. Adanya fasilitas pimpinan untuk melihat kegiatan perkuliahan.

10. Adanya fasilitas ubah password untuk mengubah password sesuai dengan username yang dimiliki.

11. Adanya fasilitas Logout untuk keluar dari sistem.

\section{B. Perancangan Data}

Perancangan Portal Kegiatan Perkuliahan ini menggunakan metode pemodelan permrograman terstruktur yaitu DFD (Data Flow Diagram).

Data Flow Diagram

1. DFD Level 0

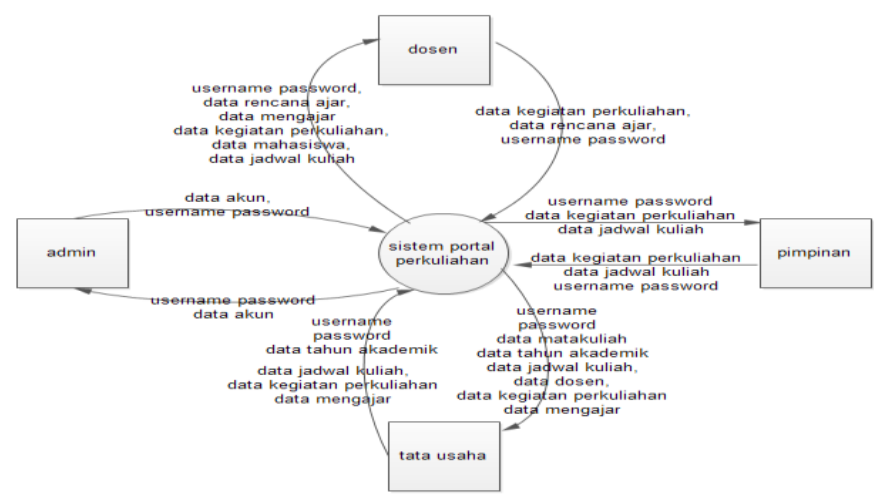

Gambar 1 DFD level 0

Pada DFD level 0 menjelaskan tentang proses di sistem portal perkuliahan. Terdiri dari empat entitas yaitu:

a. Admin

Admin dapat melakukan login, mengelola data akun dan data matakuliah. b. Tata usaha

Tata usaha dapat melakukan login, mengelola jadwal kuliah, mengelola data dosen, melihat kegiatan perkuliahan.

c. Dosen

Dosen dapat melakukan login dan mengelola kegiatan perkuliahan.

d. Pimpinan

Pimpinan dapat melakukan login dan melihat kegiatan perkuliahan. Sehingga aliran data yang masuk (input):

\section{DFD Level 1}

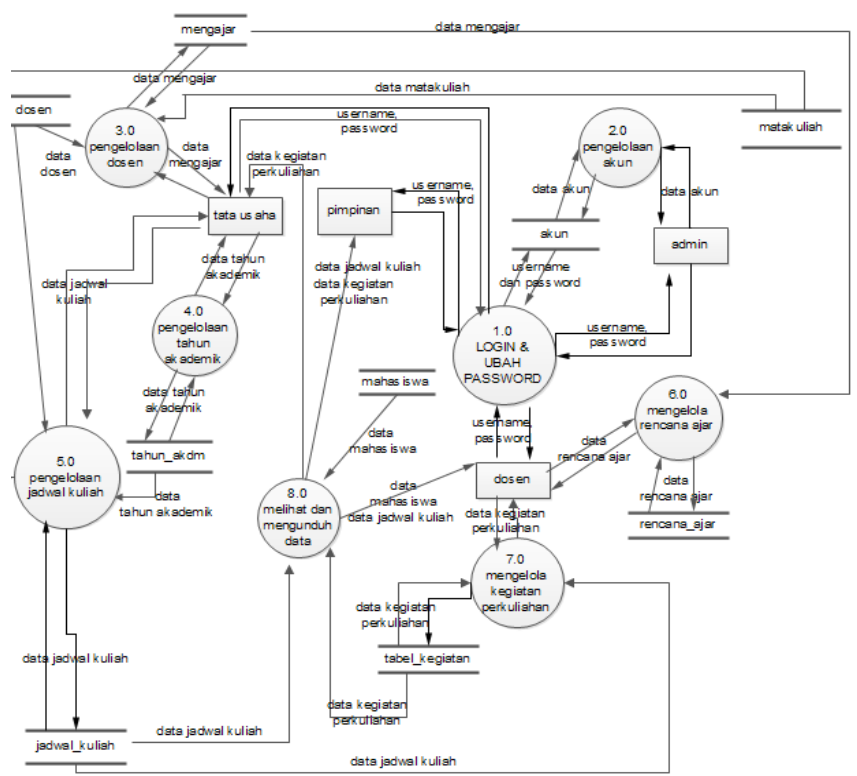

Gambar 2 DFD level 1

Tempat penyimpanan (storage) yang digunakan pada perancangan DFD level 1 adalah:

a. Akun

Merupakan tabel untuk menyimpan data akun

b. matakuliah

Merupakan tabel untuk menyimpan data matakuliah

c. dosen

Merupakan tabel untuk menyimpan data dosen

d. Mahasiswa

Merupakan tabel untuk menyimpan data mahasiswa

e. Jadwal_kuliah

Merupakan tabel untuk menyimpan jadwal perkuliahan

f. Tabel_kegiatan

Merupakan tabel untuk menyimpan materi kegiatan perkuliahan

g. Tahun_akdm

Merupakan tabel untuk menyimpan tahun akademik

h. Rencana_ajar

Merupakan tabel untuk menyimpan rencana ajar

i. Mengajar

Merupakan tabel untuk menyimpan matakuliah yang diampu dosen

Proses-proses yang terlibat pada DFD level 1 adalah

Tabel 1 Proses pada DFD level 1

\begin{tabular}{|l|l|l|l|}
\hline \multicolumn{1}{|c|}{$\begin{array}{c}\text { Nama } \\
\text { Proses }\end{array}$} & $\begin{array}{c}\text { Aliran Data } \\
\text { Masuk (input) }\end{array}$ & $\begin{array}{c}\text { Aliran Data } \\
\text { Keluar } \\
\text { (output) }\end{array}$ & Keterangan \\
\hline $\begin{array}{l}\text { Login dan } \\
\text { ubah }\end{array}$ & $\begin{array}{l}\text { Username dan } \\
\text { Password }\end{array}$ & $\begin{array}{l}\text { Username } \\
\text { dan } \\
\text { password }\end{array}$ & $\begin{array}{l}\text { Pengguna } \\
\text { melakukan } \\
\text { login untuk } \\
\text { validasi } \\
\text { mengakses } \\
\text { sistem }\end{array}$ \\
\hline
\end{tabular}




\begin{tabular}{|c|c|c|c|}
\hline & & & $\begin{array}{l}\text { portal } \\
\text { perkuliahan }\end{array}$ \\
\hline $\begin{array}{l}\text { Pengelolaan } \\
\text { akun }\end{array}$ & Data akun & Data akun & $\begin{array}{l}\text { Admin } \\
\text { dapat } \\
\text { memasukan } \\
\text { data, } \\
\text { mengubah } \\
\text { dan } \\
\text { menghapus } \\
\text { data akun } \\
\end{array}$ \\
\hline $\begin{array}{l}\text { Pengelolaan } \\
\text { tahun } \\
\text { akademik }\end{array}$ & $\begin{array}{l}\text { data tahun } \\
\text { akademik }\end{array}$ & $\begin{array}{l}\text { Data tahun } \\
\text { akademik }\end{array}$ & $\begin{array}{l}\text { Tata usaha } \\
\text { dapat } \\
\text { memasukan } \\
\text { data, } \\
\text { mengubah } \\
\text { dan } \\
\text { menghapus } \\
\text { data tahun } \\
\text { akademik }\end{array}$ \\
\hline $\begin{array}{l}\text { Pengelolaan } \\
\text { jadwal } \\
\text { kuliah }\end{array}$ & $\begin{array}{l}\text { a. Data } \\
\text { matakuliah } \\
\text { b. Data } \\
\text { dosen } \\
\text { c. Data tahun } \\
\text { akademik }\end{array}$ & $\begin{array}{l}\text { Data } \\
\text { Jadwal } \\
\text { kuliah }\end{array}$ & $\begin{array}{l}\text { Tata usaha } \\
\text { dapat } \\
\text { memasukan } \\
\text { data, } \\
\text { mengubah } \\
\text { dan } \\
\text { menghapus } \\
\text { data jadwal } \\
\text { kuliah jika } \\
\text { telah } \\
\text { melakukan } \\
\text { login }\end{array}$ \\
\hline $\begin{array}{l}\text { Pengelolaan } \\
\text { dosen }\end{array}$ & $\begin{array}{l}\text { a. Data dosen } \\
\text { b. Data } \\
\text { matakuliah }\end{array}$ & $\begin{array}{l}\text { data } \\
\text { mengajar }\end{array}$ & $\begin{array}{l}\text { Tata usaha } \\
\text { dapat } \\
\text { menambah } \\
\text { matakuliah } \\
\text { yang } \\
\text { diampu dan } \\
\text { menghapus } \\
\text { jika telah } \\
\text { melakukan } \\
\text { login }\end{array}$ \\
\hline $\begin{array}{l}\text { kegiatan } \\
\text { perkuliahan }\end{array}$ & $\begin{array}{l}\text { a.data kegiatan } \\
\text { perkuliahan } \\
\text { b. data jadwal } \\
\text { kuliah }\end{array}$ & $\begin{array}{l}\text { Data } \\
\text { kegiatan } \\
\text { perkuliahan }\end{array}$ & $\begin{array}{l}\text { Dosen } \\
\text { dapat } \\
\text { mengisi } \\
\text { materi } \\
\text { kegiatan } \\
\text { perkuliahan } \\
\text { jika telah } \\
\text { melakukan } \\
\text { login }\end{array}$ \\
\hline $\begin{array}{l}\text { Rencana } \\
\text { kegiatan }\end{array}$ & Data mengajar & $\begin{array}{l}\text { Data } \\
\text { rencana } \\
\text { kegiatan }\end{array}$ & $\begin{array}{l}\text { Dosen } \\
\text { dapat } \\
\text { mengelola } \\
\text { rencana } \\
\text { kegiatan }\end{array}$ \\
\hline $\begin{array}{l}\text { Melihat dan } \\
\text { unduh data }\end{array}$ & & $\begin{array}{l}\text { A. Data } \\
\text { mahasis } \\
\text { wa } \\
\text { b. Data } \\
\text { kegiatan } \\
\text { perkuliah } \\
\text { an } \\
\text { c. Data } \\
\text { jadwal }\end{array}$ & $\begin{array}{l}\text { Dosen } \\
\text { dapat } \\
\text { melihat } \\
\text { data } \\
\text { mahasiswa } \\
\text { Pimpinan } \\
\text { dapat } \\
\text { melihat } \\
\text { kegiatan } \\
\text { perkuliahan }\end{array}$ \\
\hline
\end{tabular}

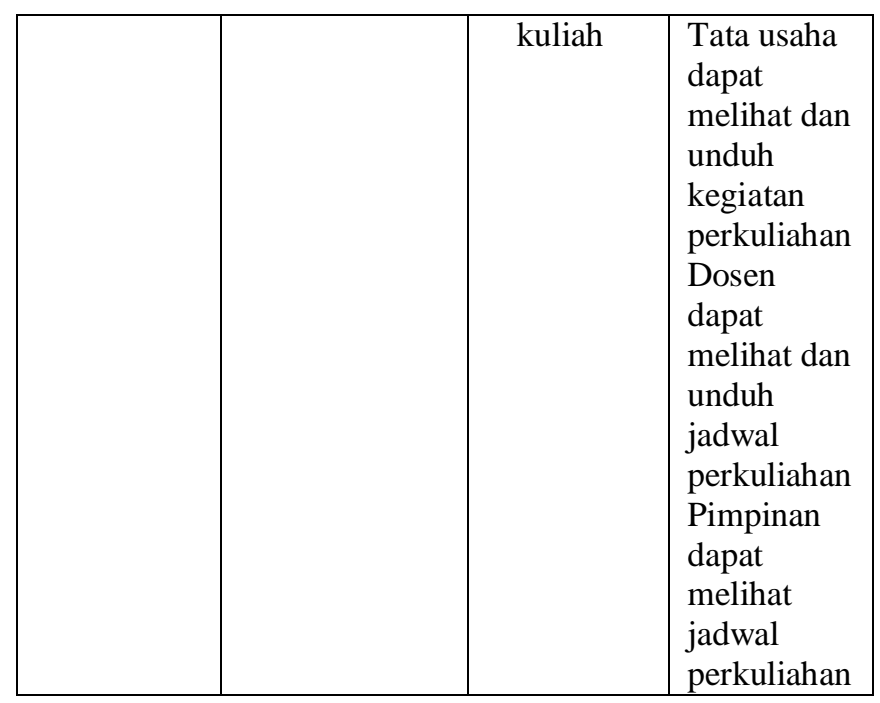

3. Perancangan Basis Data (ERD)

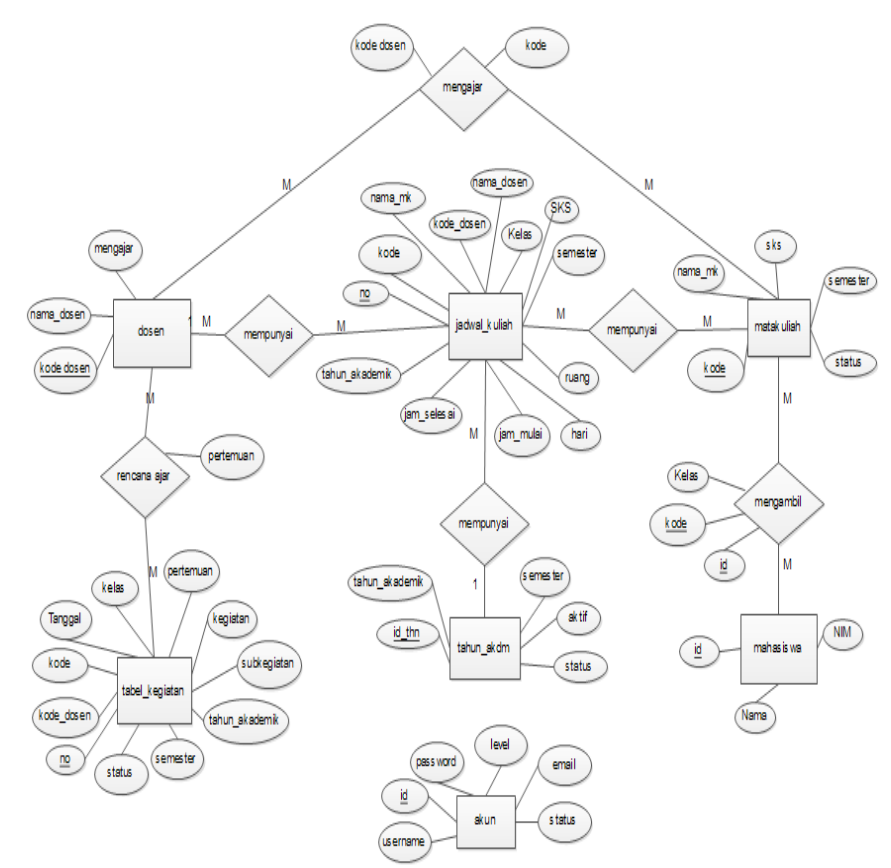

Gambar 3. Entity-Relationship Diagram (ERD)

\section{PENGUJIAN SISTEM}

\section{A. Pengujian}

Proses pengujian menggunakan metode blackbox dibagi menurut fungsi dari masing-masing menu sesuai dengan kegunaannya.

Tabel 2 Pengujian menu umum

\begin{tabular}{|l|l|}
\hline Nama Pengujian & Hasil Pengujian \\
\hline Pengujian menu login & Berhasil \\
\hline Pengujian menu logout & Berhasil \\
\hline Pengujian ubah password & Berhasil \\
\hline Pengujian menu user & Berhasil \\
\hline Pengujian tambah user & Berhasil \\
\hline Pengujian edit user & Berhasil \\
\hline Pengujian hapus user & Berhasil \\
\hline Pengujian menu daftar matakuliah & Berhasil \\
\hline Pengujian menu jadwal kuliah & Berhasil \\
\hline $\begin{array}{l}\text { Pengujian menu tambah jadwal } \\
\text { kuliah }\end{array}$ & Berhasil \\
\hline Pengujian menu edit jadwal kuliah & Berhasil \\
\hline
\end{tabular}

JTSiskom - 159 


\begin{tabular}{|l|l|}
\hline $\begin{array}{l}\text { Pengujian menu hapus jadwal } \\
\text { kuliah }\end{array}$ & Berhasil \\
\hline $\begin{array}{l}\text { Pengujian Menu tambah tahun } \\
\text { akademik }\end{array}$ & Berhasil \\
\hline $\begin{array}{l}\text { Pengujian Menu Ubah Tahun } \\
\text { akademik }\end{array}$ & Berhasil \\
\hline $\begin{array}{l}\text { Pengujian menu hapus tahun } \\
\text { akademik }\end{array}$ & Berhasil \\
\hline Pengujian menu dosen & Berhasil \\
\hline $\begin{array}{l}\text { Pengujian menu tambah matakuliah } \\
\text { dosen }\end{array}$ & Berhasil \\
\hline Pengujian menu hapus dosen & Berhasil \\
\hline $\begin{array}{l}\text { Pengujian menu kegiatan per- } \\
\text { kuliahan oleh pengguna dosen }\end{array}$ & Berhasil \\
\hline $\begin{array}{l}\text { Pengujian menu kegiatan perkuliah- } \\
\text { an oleh pengguna tatausaha dan } \\
\text { pimpinan }\end{array}$ & Berhasil \\
\hline Pengujian menu peserta matakuliah & Berhasil \\
\hline
\end{tabular}

\section{KESIMPULAN DAN SARAN}

\section{A. Kesimpulan}

Berdasarkan hasil pengujian dan analisis aplikasi Portal Kegiatan Perkuliahan, maka dapat disimpulkan hal-hal sebagai berikut:

1. Aplikasi Portal Kegiatan Perkuliahan dapat berjalan sesuai yang diharapkan pada web browser Google Crome dan Mozila Firefox.

2. Pada web browser Internet Explorer tampilan aplikasi Portal Kegiatan Perkuliahan tidak sesuai yang diharapkan pada.

3. Aplikasi Portal Kegiatan Perkuliahan dapat berjalan sesuai dengan skenario sistem yang telah dirancang.

4. Pengujian aplikasi Portal Kegiatan Perkuliahan dengan menggunakan black box berhasil sesuai dengan hasil yang diharapkan.

5. Berdasarkan pengujian, semua menu pada Aplikasi Portal Perkuliahan sudah berjalan sesuai dengan fungsinya

B. Saran

Berdasarkan pengujian terhadap aplikasi Portal Kegiatan Perkuliahan, yang telah dibuat, dapat diberikan beberapa saran sebagai berikut:

1. Aplikasi Portal Kegiatan Perkuliahan dapat dikembangkan lebih lanjut agar dapat terhubung dengan Sistem Informasi Akademik yang terdapat di Jurusan Sistem Komputer

2. Aplikasi Portal Kegiatan Perkuliahan dapat ditambahkan fungsi melihat presentasi kehadiran tiap mahasiswa dari sisi dosen

\section{Daftar Pustaka}

[1] Aditama, R." Sistem Informasi Akademik kampus Berbasis WEB dengan PHP". Yogyakarta: Loko Media, 2012.

[2] Arief, M.R. "Pemrograman Web Dinamis Menggunakan PHP \& MySQL". Yogyakarta: Andi, 2011.

[3] Dwiartara, L."Menyelam \& Menaklukan Samudra PHP". Ilmu Website, 2010.

[4] Hadisaputra, A. "HTML \& CSS Fundamental Dari Akar Menuju Daun". Ilmu Website, 2010.

[5] Sommerville, I." Software Engineering 6th Edition (6th ed.)". Massachusetts: Pearson Education. 2000.

[6] Indrajani. "Perancangan Basis Data dalam All in 1". Jakarta: Elex Media Komputindo, 2011.

[7] Nugroho, B. "Aplikasi Pemrograman Web Dinamis dengan PHP dan MySQL". Yogyakarta: Gava Media, 2004.

[8] Raharjo, B., Heryanto, I. \& RK, Enjang. "Modul pemrograman WEB(HTML, PHP,\& MYSQL)". Bandung: Modula, 2012.

[9] S, Rosa. A. \& Shalahuddin, "M. Modul Pembelajaran Rekayasa Perangkat Lunak (Terstruktur Dan Berorientasi Objek)". Bandung: Modula, 2011.

[10] Solichin, A. "MySQL 5: Dari Pemula Hingga Mahir". Jakarta: achmatim.net, 2010.

[11] Sugiarta, I. G. R. A., \& Puspita, N. N. H."Pengembangan Sistem Kehadiran Dosen STIKOM Bali". (STMIK) STIKOM Bali, 2011.

[12] www.jalinas.staff.gunadarma.ac.id yang diakses pada tanggal 20 Mei 2013 pukul 12:05:05 WIB

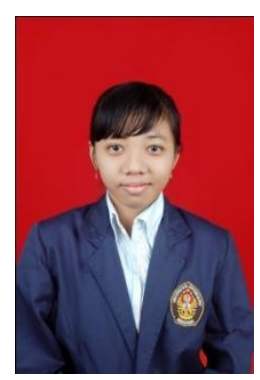

Dyah Mustika Nency Widowati, lahir di Purwodadi, 19 November 1990.Telah menempuh pendidikan dasar di SD Negeri Rogojembangan 03 Semarang. Melanjutkan ke SMPN 29 Semarang, dan meneruskan Pendidikan tingkat atas di SMA Sint Louis Semarang, lulus tahun 2009. Dari tahun 2009 sampai saat ini tengah menyelesaikan pendidikan Strata Satu di Program Studi Teknik Sistem Komputer, Universitas Diponegoro, Semarang, Indonesia Angkatan Tahun 2009. 
